\title{
Thrombotic thrombocytopenic purpura in the course of systemic lupus erythematosus in a 15-year-old girl
}

\author{
HANNA SZYMANIK-GRZELAK', JOANNA PRZYCHODZEN' ${ }^{\prime}$, ANNA STELMASZCZYK-EMMEL ${ }^{2}$, \\ MAEGORZATA PAŃCZYK-TOMASZEWSKA ${ }^{l}$
}

'Department of Pediatrics and Nephrology, Medical University of Warsaw, Poland

${ }^{2}$ Department of Laboratory Diagnostics and Clinical Immunology of Developmental Age, Medical University of Warsaw, Poland

\begin{abstract}
Systemic lupus erythematosus (SLE) concomitant with thrombotic thrombocytopenic purpura (TTP) in children is rarely diagnosed. We report a case of a 15-year-old girl with butterfly patch, generalized edema, leg pain, anemia ( $\mathrm{Hb} 74 \mathrm{~g} / \mathrm{l})$, thrombocytopenia $\left(5 \times 10^{9} / \mathrm{l}\right)$, schistocytes in peripheral blood smear, acute kidney injury (eGFR $\left.27 \mathrm{ml} / \mathrm{min} / 1.73 \mathrm{~m}^{2}\right)$, proteinuria, and erythrocyturia. The direct Coombs test was positive, and warm antibodies $(\mathrm{Ig} G)$ were detected on red blood cells. ANA in titer $1: 2560$, low serum C3 and C4 complement level, ADAMTS13 (a disintegrin and metalloproteinase with a thrombospondin type 1 motif, member 13) activity $<4 \%$ and the presence of ADAMTS13 inhibitor were detected. In renal biopsy class $I V_{A} / V$ lupus nephritis was diagnosed. Her clinical symptoms fulfilled criteria for the diagnosis of SLE and the diagnosis of TTP. She was treated with intravenous methylprednisolone and cyclophosphamide $750 \mathrm{mg} / 1.73 \mathrm{~m}^{2} /$ monthly for six months, followed by oral prednisone with azathioprine, chloroquine, and enalapril. The long-term clinical outcome was good.

We report a case rare in adolescents, TTP related to SLE, which may suggest the need to test for ADAMTS13 activity and the presence of ADAMTS13 inhibitor in children with SLE and anemia, thrombocytopenia and rapid deterioration of renal function, to make the right therapeutic decisions.
\end{abstract}

Key words: ADAMTS13, children, hemolytic-uremic syndrome, lupus nephritis, thrombotic thrombocytopenic purpura.

(Centr Eur J Immunol 2017; 42 (4): 407-408)

\section{Introduction}

Systemic lupus erythematosus (SLE) is an autoimmune disease with multiple manifestations and varying clinical severity [1]. Hemolytic-uremic syndrome (HUS) and thrombotic thrombocytopenic purpura (TTP) are forms of thrombotic microangiopathy (TMA). Characteristic symptoms for HUS are TMA and renal failure, while TTP manifests with TMA, neurological symptoms, fever, and less commonly renal failure. Typical HUS is related to Shiga toxin producing Escherichia coli infection, while complement dysregulation leads to atypical HUS. Secondary HUS may be related to drugs, malignancies, pregnancy, and systemic disorders [2]. The severe deficiency of ADAMTS13 (a disintegrin and metalloproteinase with a thrombospondin type 1 motif, member 13 ) activity $<5 \%$ causes TTP. TTP may be secondary to SLE.

\section{Case report}

We report the case of a 15-year-old girl, with an unremarkable family history. One year earlier, she suffered from malaise and hair loss. The diagnosis of autoimmuno-hemolytic anemia was established. After six months' steroid treatment, relapse of anemia and decreased platelet count were observed due to cytomegalovirus infection. She was treated with immunoglobulins and steroids. A month later she developed pain in the lower limbs. She was admitted to the hospital with generalized edema, butterfly patch on the face, blood pressure $105 / 65 \mathrm{mmHg}$, and urine output $240 \mathrm{ml} /$ day. The neurological examination was negative. Laboratory investigations showed: hemoglobin $63 \mathrm{~g} / \mathrm{l}$, red blood cell count $2.08 \times 10^{12} / 1$; white blood cell count $3.2 \times 10^{9} / 1$; platelet count $5.0 \times 10^{9} / 1$, bilirubin total $53 \mu \mathrm{mol} / \mathrm{l}, \mathrm{LDH} 2691 \mathrm{U} / \mathrm{l}$, albumin $30 \mathrm{~g} / \mathrm{l}$; serum creatinine

Correspondence: Anna Stelmaszczyk-Emmel, Department of Laboratory Diagnostics and Clinical Immunology of Developmental Age, Medical University of Warsaw, 63A Zwirki i Wigury St, 02-091 Warsaw, Poland, tel: +48223179505 , fax: +4822317995 ,

e-mail: anna.stelmaszczyk-emmel@wum.edu.pl

Submitted: 25.09.2017; Accepted: 16.10.2017

Central European Journal of Immunology 2017; 42(4) 
$229.89 \mu \mathrm{mol} / 1$, eGFR $27 \mathrm{ml} / \mathrm{min} / 1.73 \mathrm{~m}^{2}$; in urinalysis: proteinuria $6.5 \mathrm{~g} / 1$, erythrocyturia, and leukocyturia. Urine culture was negative. Peripheral blood smear showed schistocytes. The direct Coombs test was positive, warm antibodies ( $\mathrm{IgG}$ ) were detected. The serum complement components were: $\mathrm{C} 3<0.40 \mathrm{~g} / \mathrm{l}, \mathrm{C} 4<0.08 \mathrm{~g} / \mathrm{l}$. Antinuclear antibodies (ANA) $1: 2560$; anti-dsDNA antibody $(++)$ and ADAMTS13 activity $<4 \%$ with the presence of ADAMTS13 inhibitor $62 \mathrm{UI} / \mathrm{ml}$ were detected.

In renal biopsy, mesangial proliferation, karyorrhexis, capillary loops' lobulization, infiltration of mononuclear cells in interstitium and mesangial deposition of $\mathrm{C} 3$ complement (+2/+3), $\operatorname{IgA}(+2 /+3), \operatorname{IgM}(+1 /+2), \operatorname{IgG}(+1)$ and fibrinogen $(+1)$ were present. In electron microscopy, partial thickening of capillary loops, interposition of mesangium and electron dense mesangial, subepithelial, subendothelial, and intramembranous deposits were present. Lupus nephritis $\mathrm{IV}_{\mathrm{A}} / \mathrm{V}$ was diagnosed [3]. There were no small thrombi in biopsy.

She received 10 pulses of methylprednisolone $10 \mathrm{mg} /$ $\mathrm{kg} / \mathrm{pulse}$ IV and 6 pulses of cyclophosphamide $750 \mathrm{mg} /$ $\mathrm{m}^{2} /$ monthly IV, then for 2.5 years azathioprine with prednisone, chloroquine, and enalapril. After one month's treatment normalization of ADAMTS13 activity (74\%) and ADAMTS13 inhibitor (15 UI/ml) were observed, serum C3 0.56 g/l, C4 0.11 g/l; ANA 1 : 640, anti-dsDNA antibody (+), eGFR $>60 \mathrm{ml} / \mathrm{min} / 1.73 \mathrm{~m}^{2}$. Urinalysis was normal after 2 months. After three years of treatment: serum C3 0.90 g/l, serum C4 0.11 g/l, ANA 1 : 160, anti-dsDNA antibody (-), eGFR $94 \mathrm{ml} / \mathrm{min} / 1.73 \mathrm{~m}^{2}$, urinalysis is normal.

\section{Discussion}

In our patient with anemia, thrombocytopenia and acute renal injury, the peripheral blood smear showed schistocytes, thereby indicating microangiopathic anemia, and Coombs test was positive, which may suggest two coexisting mechanisms for the development of anemia (mechanic/TMA and antibodies/SLE). The laboratory tests showed high ANA titer and very low ADAMTS13 activity with the presence of ADAMTS13 inhibitor (antibodies), so TTP secondary to SLE was suspected. In renal biopsy, SLE nephritis was diagnosed; there were no small thrombi, but only $50-75 \%$ of SLE-related TTP patients revealed in biopsy the typical features of TMA.

In SLE-related TTP, immunosuppression should be administered to control SLE activity, while plasmapheresis is considered controversial $[4,5]$. In our patient with SLE and secondary TTP related to presence of the inhibitor ADAMTS13, intravenous CYP treatment with steroids was effective, without the need of plasmapheresis.

\section{Conclusions}

In patient with SLE presenting with anemia, thrombocytopenia, and acute kidney injury, secondary TTP/HUS should be suspected and the presence of ADAMTS13 inhibitor and the ADAMTS13 activity should be tested to ensure the right therapeutic decisions. The prognosis of patients with SLE-related TTP may be good, despite very low ADAMTS13 activity, provided that immunosuppressive treatment is aggressive.

The authors declare no conflicts of interest.

\section{References}

1. Petri M, Orbai AM, Alarcón GS, et al. (2012): Derivation and validation of the Systemic Lupus International Collaborating Clinics classification criteria for systemic lupus erythematosus. Arthritis Rheum 64: 2677-2686.

2. Loirat C, Fakhouri F, Ariceta G, et al. (2016): An international consensus approach to the management of atypical hemolytic uremic syndrome in children. Pediatr Nephrol 31: 15-39.

3. Weening J, D'Agati V, Schwartz M, et al. (2004): The classification of glomerulonephritis in systemic lupus erythematosus revisited. Kidney Int 65: 521-530.

4. Bertsias GK, Tektonidou M, Amoura Z, et al. (2012): Joint European League Against Rheumatism and European Renal Association-European Dialysis and Transplant Association (EULAR/ERA-EDTA) recommendations for the management of adult and paediatric lupus nephritis. Ann Rheum Dis 71: 1771-1782.

5. Sakarcan A, Stallworth J (2001): Systemic lupus erythematosus and thrombotic thrombocytopenic purpura: a case and review. Pediatr Nephrol 16: 672-674. 